\title{
LAMINADOS CERÂMICOS NA CLÍNICA INTEGRADA
}

Luciano Bonatelli BISPO'

\section{RESUMO}

Os avanços técnico-científicos da odontologia restauradora trouxeram mudanças nos paradigmas preexistentes. A conservação da estrutura dentária e a aplicabilidade clínica dos conceitos provenientes das disciplinas básicas tornaram o binômio estética e função plenamente exequíveis. A sucessão de enganos com as restaurações estéticas adesivas diretas promovida pela degradação da parte orgânica, percolação, infiltração e cáries secundárias pode ser corrigida pelas restaurações parciais indiretas. Vitrocerâmicas que incorporam cristais alongados de dissilicato de lítio, com aumento da resistência, possibilidade de condicionamento pelo ácido fluorídrico, maior tenacidade às fraturas catastróficas, bem como, translucidez adequada para serem empregadas na região anterior da arcada dentária, tornam a prática clínica menos dispendiosa, mais confortável, mais previsível e mais resolutiva. O objetivo deste trabalho é ilustrar um caso clínico de facetas anteriores, como alternativa à ansiedade da paciente e como correção das forças de segregação que estavam presentes, devido a resultados frustrantes de terapias odontológicas adesivas anteriores.

PALAVRAS-CHAVE: CERÂMICA, FACETAS DENTÁRIAS, ESTÉTICA DENTÁRIA

\section{LAMINATE VENEERS IN MULTIDISCIPLINARY CLINIC}

\begin{abstract}
The technical-scientific advances of restorative dentistry have brought changes about the preexisting paradigms. The conservation of the dental structure and the clinical applicability of the concepts from the basic disciplines have made the aesthetic binomial and function fully feasible. The succession of mistakes with the direct adhesive aesthetic restorations promoted by the organic part degradation, percolation, infiltration and secondary caries can be corrected by indirect partial restorations. Glass-ceramics that incorporate elongated crystals of lithium disilicate, with increased resistance, possibility of conditioning by hydrofluoric acid, greater tenacity to catastrophic fractures, and adequate translucency to be used in the anterior region of the dental arch, make the clinical practice less expensive, more comfortable, more predictable and more resolutive. The aim of this paper is to illustrate a clinical case of anterior laminate veneers, as an alternative to the anxiety of the patient, and as a correction of the segregation's forces that were present due to the frustrating results of previous adhesive dental therapies.
\end{abstract}

KEY WORDS: CERAMICS, DENTAL VENEERS, DENTAL ESTHETICS

1 Doutor em Dentística pela FOUSP. Especialista em Implantodontia 
ISSN 1983-5183

\section{INTRODUÇÃO}

A evolução dos materiais odontológicos e das técnicas restauradoras adesivas proporcionou a resolução clínica de situações anteriormente inimagináveis. O conceito de uma odontologia minimamente invasiva, pautada na conservação da estrutura dentária e no protocolo terapêutico sucessivo do mais conservador para o mais invasivo, revolucionou a abordagem das queixas e condições iniciais dos pacientes que buscam o consultório odontológico'.

A mínima intervenção preconiza a detecção precoce da lesão de cárie e sua avaliação de risco, a remineralização do esmalte e da dentina, medidas preventivas contra a doença cárie, uma intervenção operatória mínima, bem como a maximização no reparo de restaurações em detrimento de sua substituição sem critério, evitando-se um maior desgaste da estrutura dentária².

Entretanto, a microabrasão, o clareamento dentário, as restaurações adesivas estéticas diretas e até os fragmentos cerâmicos, muitas vezes não conseguem solucionar desarmonias e forças de segregação excessivas. Assim, busca-se um material restaurador que tenha biocompatibilidade, devolva a cosmética, seja estético dentro dos padrões vigentes, que mimetize as variações e fenômenos ópticos naturais e tenha longevidade por suas propriedades mecânicas, para ser utilizado em dentes anteriores ${ }^{3}$.

Quando em 2/3 ou mais da estrutura dentária, esta fica de alguma forma comprometida; para que se consiga corrigir discrepâncias de cor, forma, textura, função e posicionamento dos elementos na arcada, dispõe-se de restaurações parciais que visam recobrir as superfícies vestíbulo-proximais e incisais dos dentes anteriores. As facetas ou lâminas cerâmicas empregadas de forma indireta (com auxílio de um técnico de laboratório ou ceramista) constituem a melhor maneira contemporânea de devolver os requisitos necessários para um sorriso harmônico e funcional².

O objetivo deste trabalho é descrever e ilustrar um caso clínico em que os elementos dentários anteriores superiores foram reabilitados com facetas cerâmicas, complementares a protocolo clínico reabilitador, devolvendo a estética, autoestima, função, fonação e deglutição ao paciente odontológico.

\section{CASO CLÍNICO}

Paciente gênero feminino, leucoderma, compareceu à clínica odontológica de serviço público com a queixa principal de ausência dentária de elementos mandibulares do lado direito. Ao exame clínico, a paciente apresentava contenção posterior de mordida, com dentes anteriores extensivamente restaurados, manchamentos e alterações generalizadas da cor dentária e dos materiais restauradores adesivos. Após raspagem e polimento coronário e radicular, propôs-se regularização do arco côncavo da gengiva marginal livre na arcada superior por meio de cirurgia ressectiva para aumento de coroa clínica. A paciente não aceitou tal procedimento. Assim, implantes osseointegrados foram realizados na mandíbula do lado edentado, em dois estágios cirúrgicos, seguindo-se o protocolo tradicional expectante. Contudo, a insatisfação da paciente estava focada na região anterior do sorriso, uma vez que comprometia o comportamento social e gerava extrema ansiedade.

Após seleção de cor (Quadro 1), com escala tradicional para cerâmica, foi feita moldagem com alginato irreversível da arcada superior e inferior. $O$ molde obtido da arcada superior foi vazado em gesso Paris Tipo 1. Após cristalização do modelo, o técnico em prótese dentária realizou enceramento para correção das fraturas, bem como do posicionamento dos elementos anteriores. 0 modelo foi submerso em água e após 5 
Bispo LB. Laminados cerâmicos na clínica integrada. Rev. Odontol. Univ. Cid. São Paulo 2018 jan-mar; 30(1): 83-94

ISSN 1983-5183

minutos, para que o material de moldagem não grude, foi feito um molde com material pesado com silicone por reação por adição. Foi utilizado material pesado, com papel celofane interposto para espaço numa segunda moldagem, para obtenção de molde com o material leve injetado com pistola de automistura nos dentes do modelo e no molde pesado.

Quadro 1. Protocolo clínico para a confecção de laminados cerâmicos (Adaptado de Fonseca RB', 2017).

\section{PROTOCOLO CLÍNICO}

Moldagem inicial + Planejamento estético (Dentes + Periodonto)

Fotografias + Aferição de cor

Clareamento dentário

Enceramento + Mock-up

Cirurgia periodontal (se necessário)

Preparos

Moldagem final + Seleção de cor

Prova (Try-in)

Cimentação adesiva

Após obtenção do molde, foi injetada resina bisacrílica na região correspondente de canino a canino, e o molde foi levado em posição na boca, aguardando-se o tempo de polimerização da resina bisacrílica por 5 minutos. Após remoção do molde, a paciente pôde verificar um "mock-up" de como os dentes ficariam posicionados, caso fossem realizados preparos e cimentação de coroas cerâmicas. A cor da resina bisacrílica selecionada foi mais clara do que dos dentes a pedido da paciente. A paciente ficou entusiasmada com o resultado obtido. A camada de dispersão, não polimerizada em contato com o oxigênio atmosférico, foi removida com álcool isopropílico e chumaços de algodão. Os excessos foram removidos com brocas multilaminadas de 12 lâminas, polimento feito com borrachas abrasivas para resina composta tradicional e a paciente foi dispensada por uma semana, para que pudesse compartilhar os resultados de cor e posicionamento do "mock-up" com seus familiares.

Após uma semana o "mock-up" foi removido (Figura 1) e preparos foram executados para a confecção de facetas cerâmicas. Durante a fase do preparo, constataram-se inúmeras restaurações de cavidades de Classe III. Devido ao comprometimento proximal, optou-se por remover a região proximal num preparo atípico (Figura 2), que preservou parcialmente somente a face palatina. Após preparos e acabamentos de canino a canino, foram inseridos no interior dos sulcos gengivais (Figura 3) fios de numeração 00 (zero-zero). Foi realizada moldagem com silicone de reação por adição com material pesado com celofane interposto, sendo, posteriormente, removido e injetado material leve em segunda moldagem no molde e nos dentes, com remoção concomitante dos fios de afastamento e execução de jatos de ar leves, com seringa tríplice, para melhor penetração do material leve no interior da região do sulco, com o afastamento vertical e horizontal promovido. 


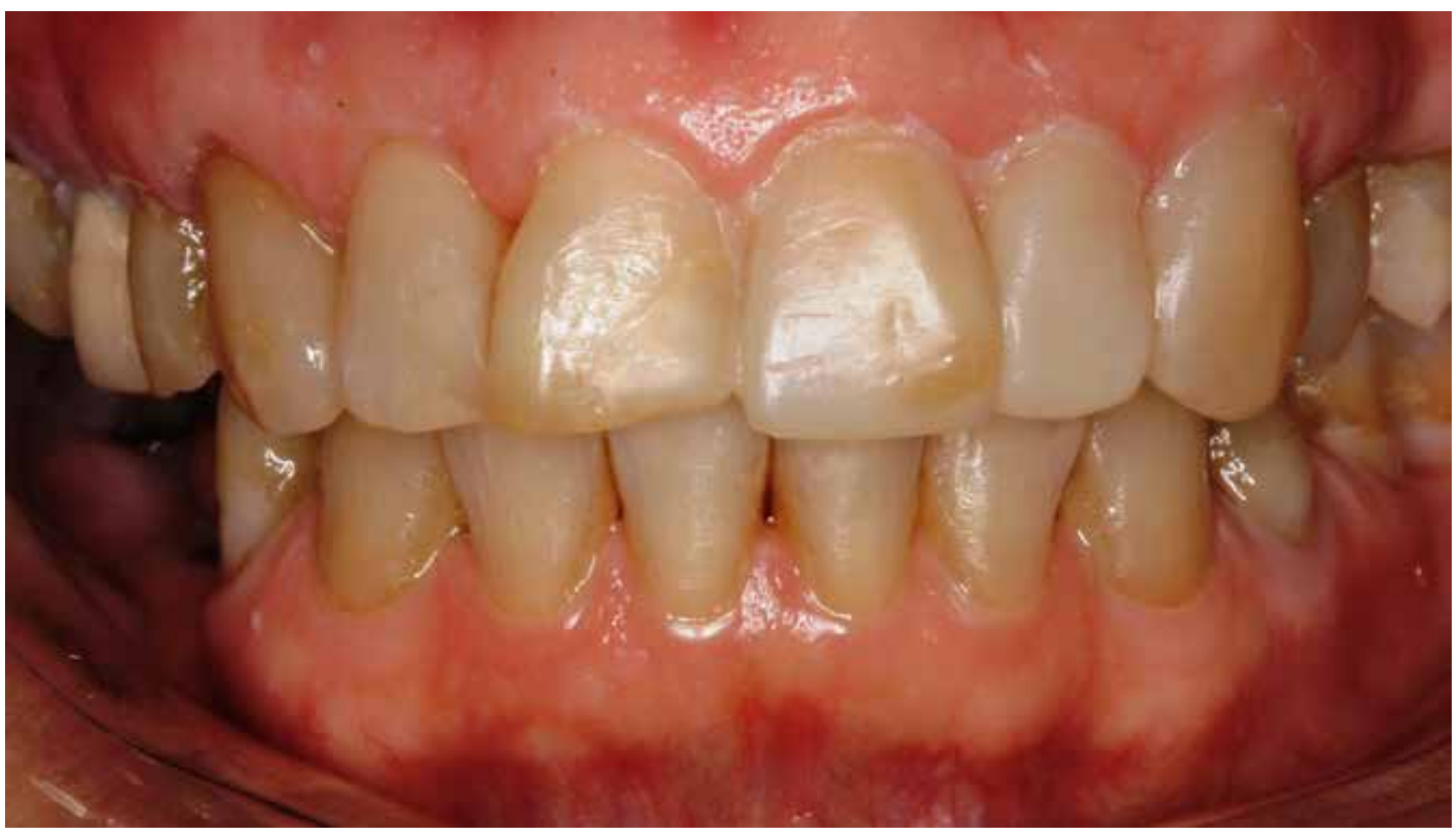

Figura 1. Paciente com "mock-up" do lado esquerdo, até canino, e com dentes manchados, quebrados e escurecidos do lado direito.

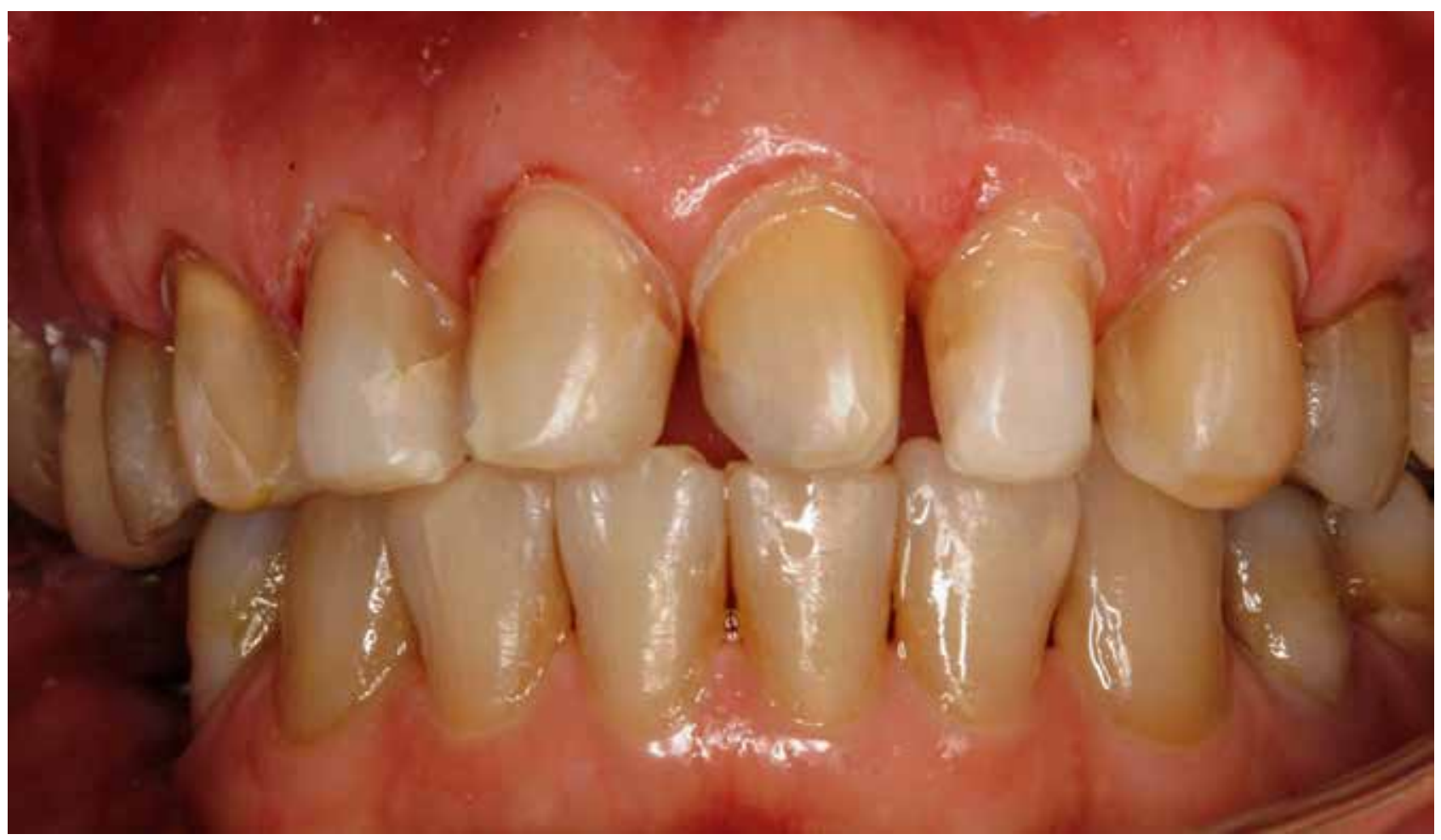

Figura 2. Preparos atípicos realizados de canino a canino com desgaste das interproximais, devido a múltiplas restaurações de cavidades de classe III insatisfatórias. 


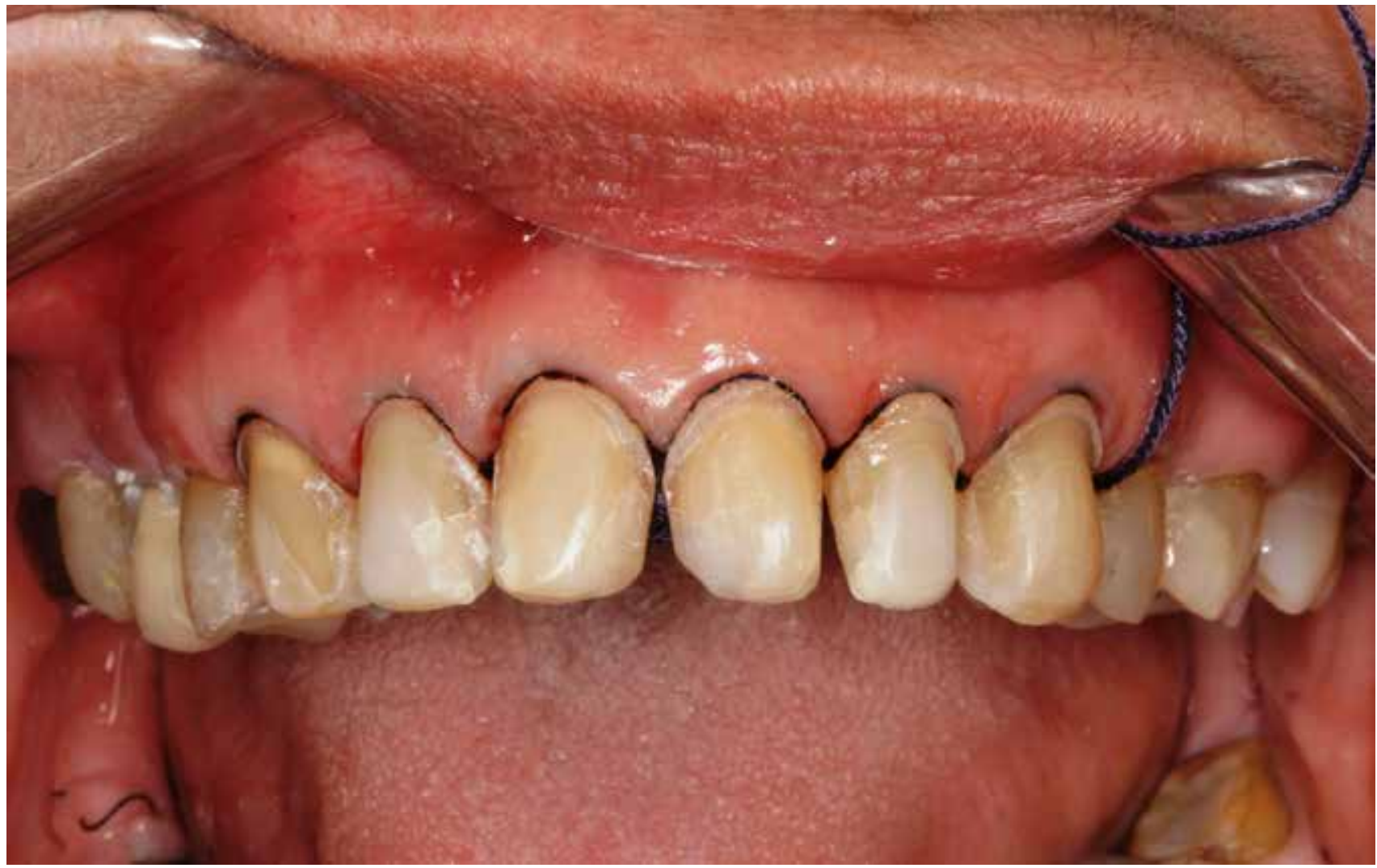

Figura 3. Inserção de fio zero-zero no interior dos sulcos gengivais dos dentes preparados.

O molde obtido e analisado com lupa de aumento de 3.5 vezes (Figura 4) foi enviado ao técnico para confecção de lâminas cerâmicas. Novo "mock-up" serviu como coroas provisórias até que as peças estivessem prontas (Figura 5). As peças ou lâminas cerâmicas, feitas com dissilicato de lítio foram maquiadas com pigmentação extrínseca e provadas após uma semana. Foram utilizados fita de papel carbono fino nas interproximais e carbono líquido na região interna das facetas. Após ajuste, com as peças devidamente provadas, foi feito condicionamento com ácido fosfórico $37 \%$ durante 30 segundos em esmalte e 15 segundos em dentina nos dentes e abundante rinsagem por tempo superior ao de condicionamento. Adesivo com polimerização dual foi friccionado nos preparos com agitação vigorosa para evaporação do solvente, sem que houvesse fotopolimerização. Na parte interna das facetas, após jateamento com óxido de alumínio $27 \mu \mathrm{m}$ (micrômetros), promovido pelo técnico no laboratório, foi feito condicionamento interno com ácido hidrofluorídrico $10 \%$ por 20 segundos $4,5,6$. Após o tempo, as facetas foram levadas em ultrassom, para remoção dos debris de condicionamento, por 5 minutos em água deionizada. Após secagem natural, as peças receberam, internamente, aplicação de silano em 2 camadas e aguardou-se 2 minutos para secagem, sem fotopolimerização. 
Bispo LB. Laminados cerâmicos na clínica integrada. Rev. Odontol. Univ. Cid. São Paulo 2018 jan-mar; 30(1): 83-94

ISSN 1983-5183

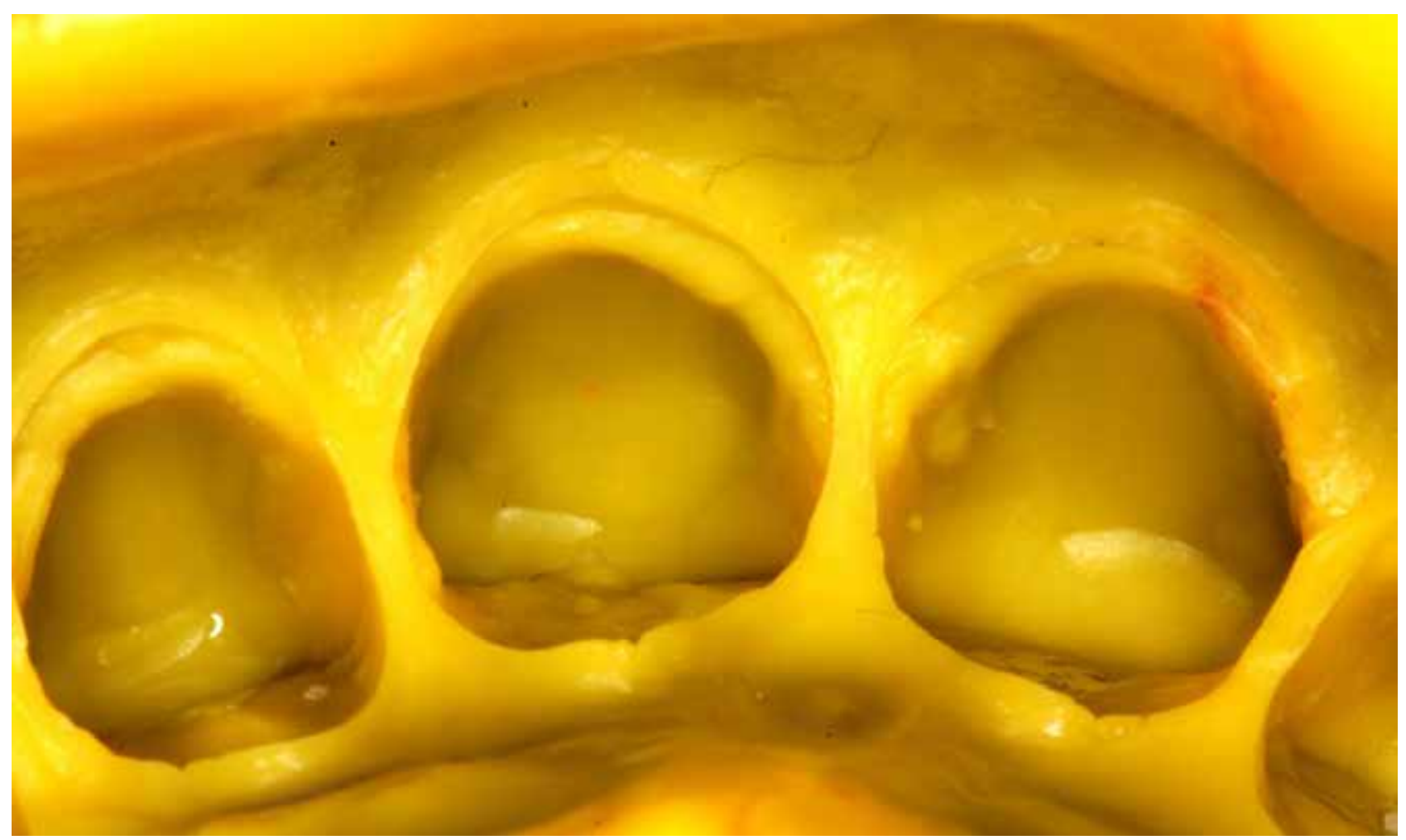

Figura 4. Molde obtido com silicone de reação por adição.

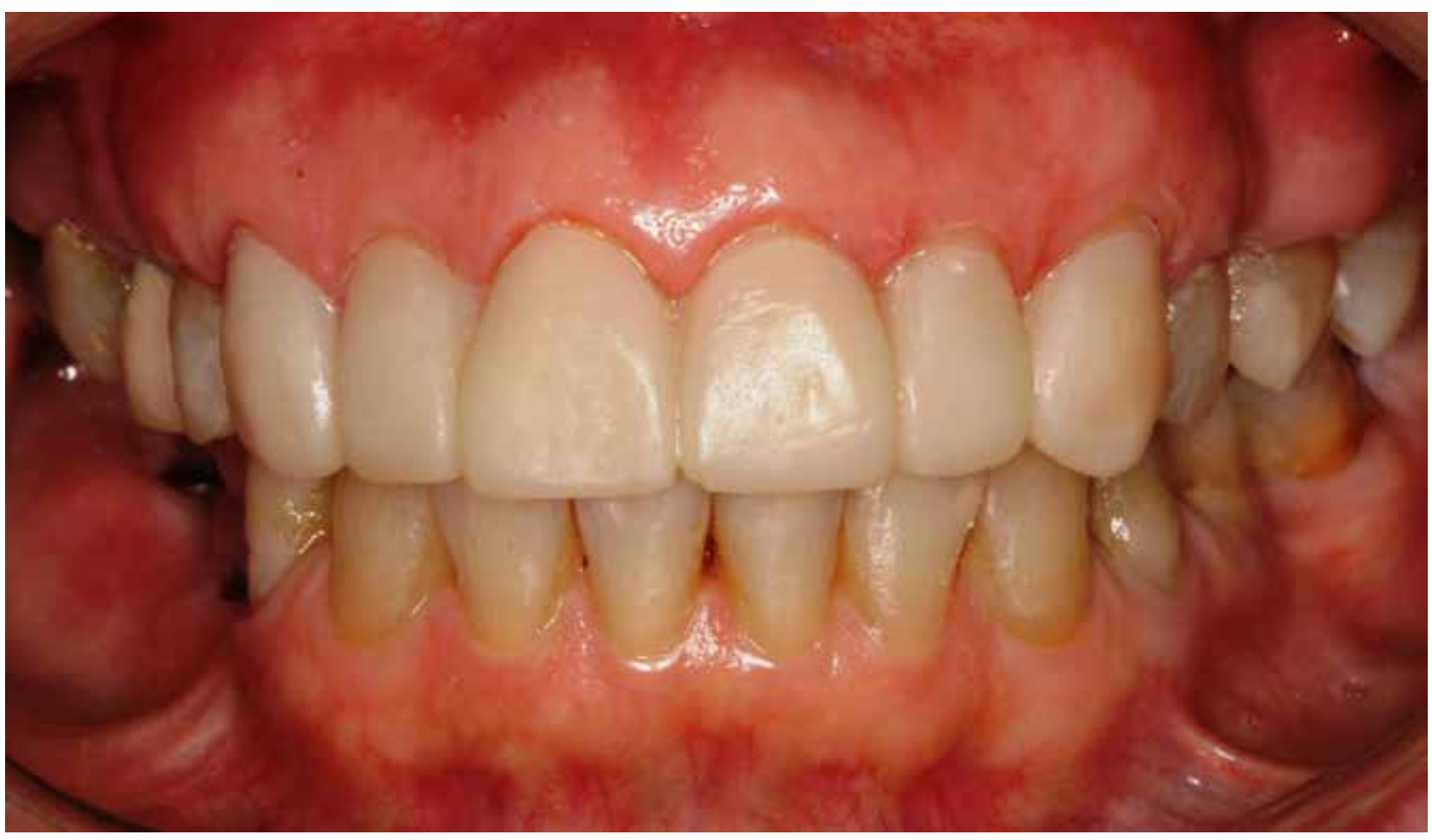

Figura 5. "Mock-up" que serviu como coroas provisórias até a execução das facetas cerâmicas. 
ISSN 1983-5183

Cimento resinoso adesivo do tipo dual foi colocado na parte interna da faceta, uma por vez, e a mesma assentada no término cervical manualmente. 0 excesso extravasado foi removido com pincel descartável e fotopolimerização por tempo igual ou superior a 40 segundos executada em todas as margens da peça protética. Após polimerização, foi utilizada uma ponta de silicone com abrasivos, para polimento da interface entre a lâmina e a estrutura dentária, tendo-se em vista que o cimento resinoso nada mais é do que uma resina composta. Pôde-se notar pequenos ferimentos na gengiva marginal da paciente, devido ao polimento executado (Figura 6). Novo ajuste da oclusão foi feito, passagem de fio dental para avaliação dos pontos ou faces de contato, bem como remoção de excessos refratários de cimento resinoso (Figura 7).

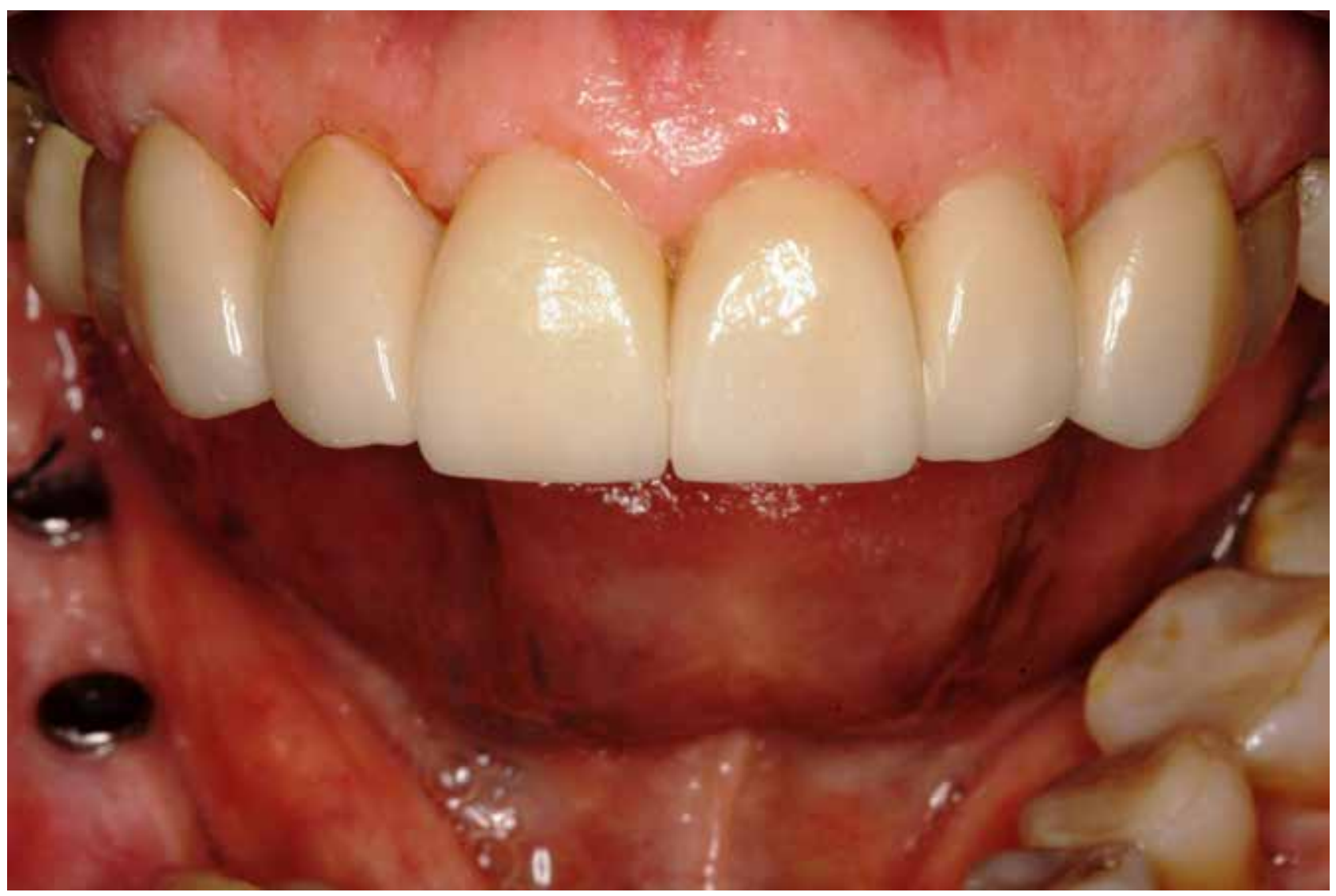

Figura 6. Lâminas cerâmicas de dissilicato de lítio cimentadas. 


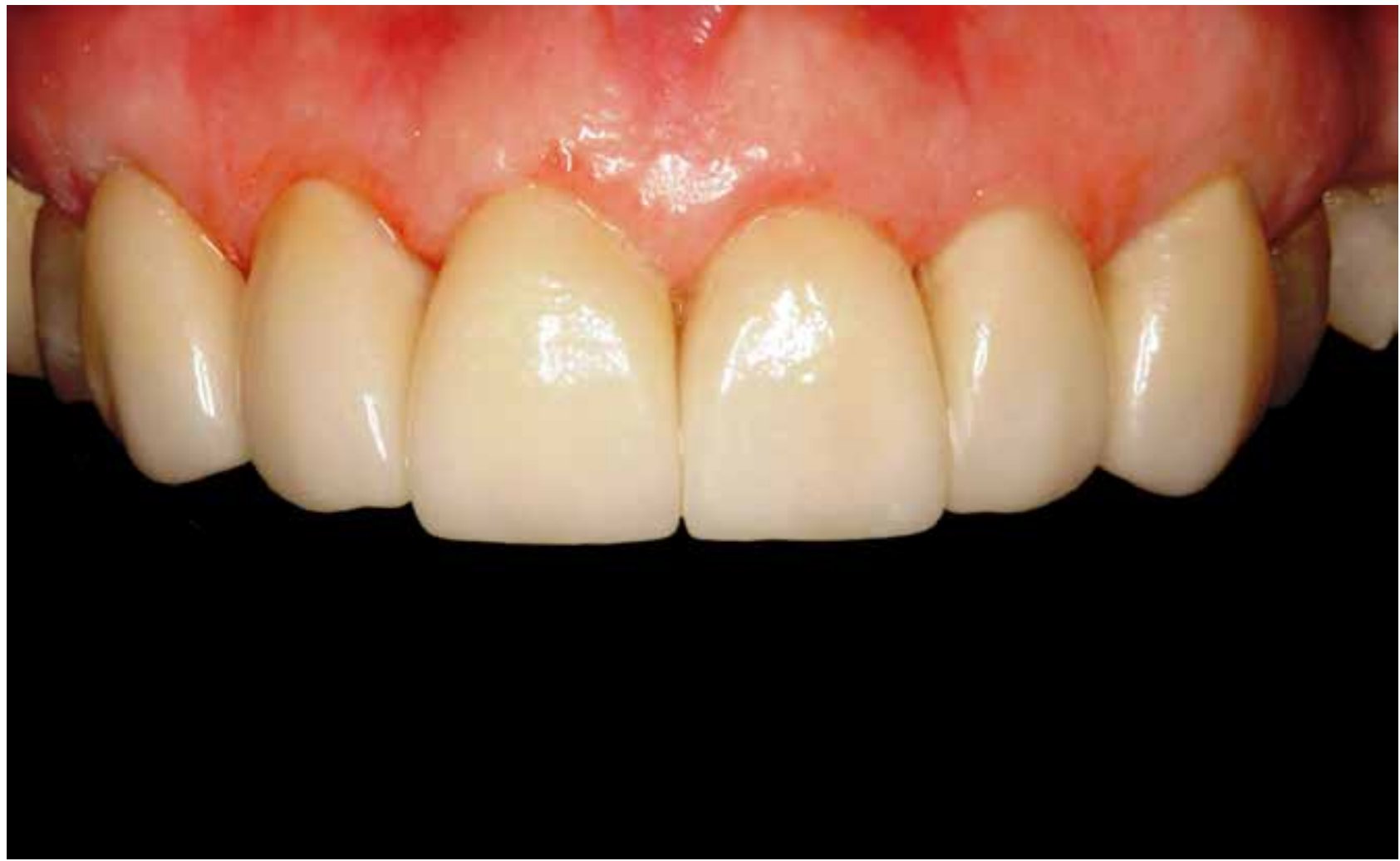

Figura 7. Lâminas cerâmicas logo após a cimentação, com gengiva levemente traumatizada após os procedimentos de remoção dos excessos de cimento resinoso e polimento da interface.

O tratamento reabilitador da paciente continua. Planeja-se a confecção de coroas cerâmicas sobre implantes e indicação de substituição de outras restaurações adesivas nos dentes posteriores, mas com a paciente mais confiante no atendimento odontológico, pela visibilidade de resultados estéticos plausíveis.

\section{DISCUSSÃO}

Laminados cerâmicos são frequentemente apresentados aos pacientes como procedimentos conservadores. Ressalva feita quando são comparados com as coroas totais. Na realidade tal associação é equivocada, pois o termo conservador se refere ao não desgaste dentário. 0 preparo para uma faceta cerâmica remove em torno de $30 \%$ de estrutura dentária. Torna-se responsável a definição do que seja invasivo, não invasivo e minimamente invasivo. Os procedimentos invasivos são aqueles que promovem a penetração do organismo por meio de instrumentos cirúrgicos. São identificados como agressivos, já que influenciam na mudança ou no formato anatômico de alguma região corporal. Tendem a ser de longa duração, com pós-operatório com controle mais apurado. Um procedimento não invasivo de nenhuma maneira penetra o paciente, nem com agulha, nem com instrumentos; como exemplo maior temos o emprego dos Rx. Os procedimentos minimamente invasivos não são agressivos e nem penetram o organismo, têm o ato operatório com curto intervalo de tempo e os pacientes retornam rapidamente à rotina, exemplo das aplicações de toxina botulínica. Consequentemente, afirma-se que um preparo para confecção de um laminado cerâmico é minimamente invasivo quando comparado a um preparo para coroa total, contudo, nem de longe conservador,8. O que pode ser constatado com o caso clínico descrito, em que havia problemas generalizados, como: restaurações adesivas diretas com manchamentos e percolações, 
Bispo LB. Laminados cerâmicos na clínica integrada. Rev. Odontol. Univ. Cid. São Paulo 2018 jan-mar; 30(1): 83-94

ISSN 1983-5183

alterações de forma em vários elementos, fraturas incisais; também, tratamentos odontológicos sucessivos, como clareamento, com dispêndio financeiro, morbidade dentária progressiva e insatisfação psicológica. Os preparos foram realizados de forma invasiva, tendo-se em vista um desgaste maior do que $30 \%$ do volume dentário, devido às múltiplas restaurações adesivas insatisfatórias, que necessitaram ser removidas, principalmente nas proximais, com um desgaste modificado que deixou apenas a face palatina parcialmente intocada.

O dissilicato de lítio para a confecção de trabalhos estéticos é uma das maiores revoluções na Odontologia Contemporânea9. A cerâmica à base de dissilicato de lítio é composta por uma matriz de cerâmica vítrea enriquecida com cristais alongados de dissilicato de lítio (60 a 65\%). Reformulações atuais, como o IPS e-max Press ou IPS e-max CAD (Ivoclar Vivadent) demonstram em torno de $65 \%$ de cristais de dissilicato de lítio, com 34\% de fase vítrea e, no máximo, 1\% de porosidades internas. 0 sistema IPS e-max permite duas possibilidades: infraestrutura de dissilicato com posterior revestimento de porcelana feldspática ou estrutura monolítica com pastilha de cor e translucidez indicada para a finalização do caso ${ }^{10}$. As cerâmicas reforçadas (vitrocerâmicas) possuem maior tenacidade, por resistirem à propagação de trincas e defeitos estruturais internos, quando comparadas às predecessoras. Os cristais se distribuem de forma a potencializarem uma tensão compressiva local na matriz vítrea, rodeando os cristais, defletindo trincas. Tais cristais de dissilicato de lítio são alongados, formando uma rede intrincada após o processo de ceramização, preenchendo-se os poros e espaços vazios com o vidro. Os cristais em formato de arroz, por se disporem entrelaçados, interpõem uma intrincada rede que dificulta a propagação das trincas entre planos, exigindo-se grande força de deflexão e intensos desvios para que a fratura catastrófica se processe de forma simplificada, como em outros tipos de porcelana, como a feldspática, por exemplo (Organograma 1). Tal material possui uma resistência aumentada, associada a uma alta translucidez requerida em regiões aparentes, portanto estéticas, da arcada"1".

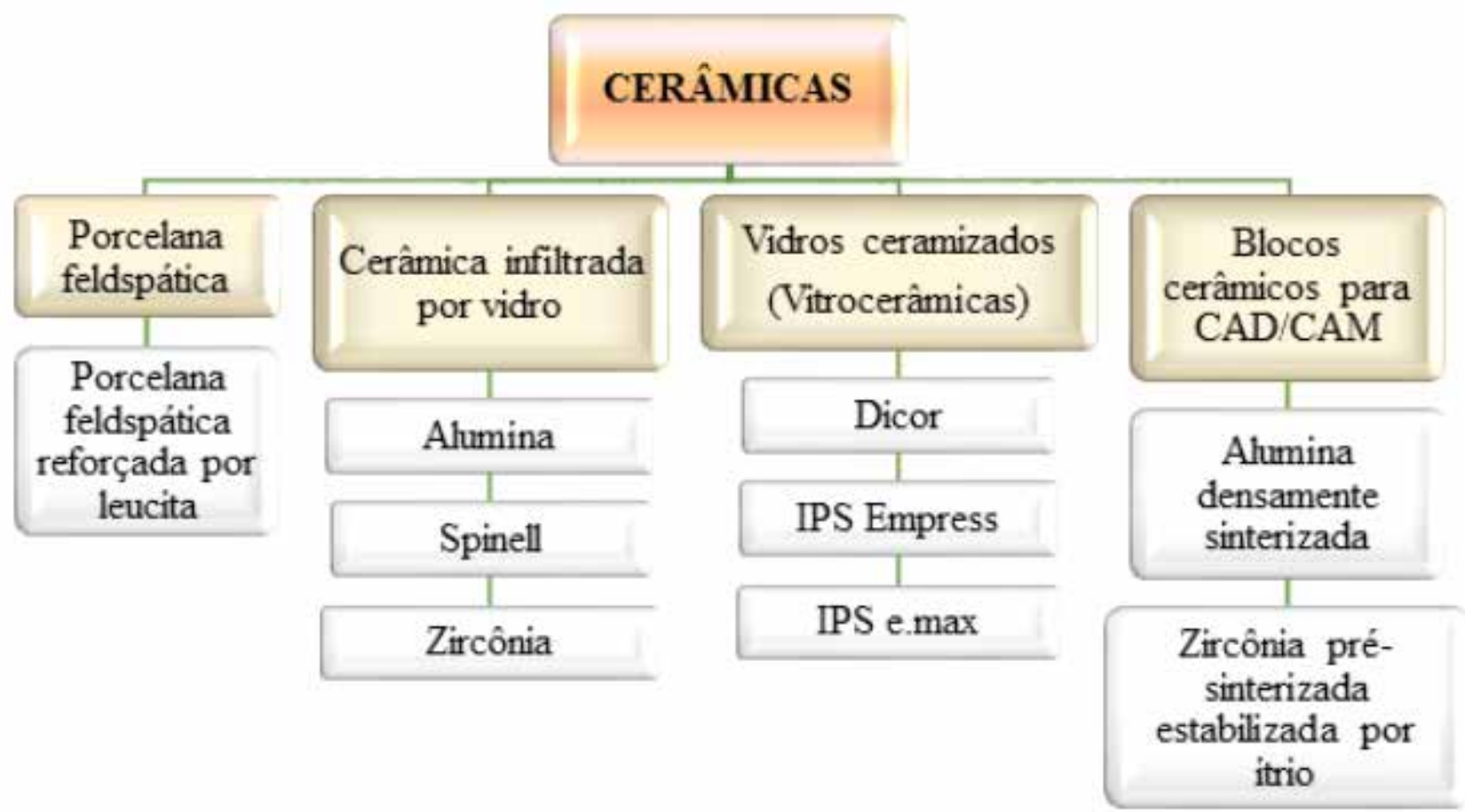

Organograma 1. Esquema com classificação simplificada das cerâmicas odontológicas (Adaptado de Chain MC10, 2013). 
ISSN 1983-5183

Fragmentos e lentes de contato cerâmicas representam inovações pela ausência ou desgaste minimizado da estrutura dentária. Representam a concepção ideal de grande estabilidade e menor espessura de preparo dentário. Todavia, ainda assim, apesar da alta resistência, são materiais friáveis, sujeitos a fraturas catastróficas. Não são tratamentos, como se considera erroneamente, reversíveis, pois não se pode remover uma cerâmica fortemente aderida ao esmalte sem envolvê-lo de alguma maneira' ${ }^{12}$.

O sucesso clínico comprovado dos laminados cerâmicos por alguns autores: de 97,5\% em 7 anos de acompanhamento ${ }^{13}$; de $91 \%$ em 10 anos $^{14}$; outro de $94,4 \%$ em 12 anos $^{15}$. Convém elucidar a execução por um ou, no máximo, dois operadores devidamente calibrados e experientes na técnica. Contrariamente, nos multicentros, trabalhos analisados mostram uma sobrevida média de $53 \%$ das facetas cerâmicas sem intervenção em 10 anos $^{16}$. Esse número parece mais elucidativo do que ocorre na clínica diária, uma vez que a observação atenta demonstra uma procura corriqueira de pacientes para a troca de laminados.

Falhas nos laminados podem ser reparadas na maioria das situações. Contudo, demonstram problemas estéticos marginais, como manchamentos e aparentes linhas interfaciais pela diferença dos materiais cerâmicos e estrutura dentária ${ }^{17}$. A remoção das facetas com pontas diamantadas, que cortam por desgaste ou abrasão, inevitavelmente, envolverá maior quantidade de tecido dental num inevitável repreparo.

Pacientes ansiosos e com altas expectativas de senso estético, com tratamentos preliminares com resinas compostas diretas insatisfatórias ou mesmo tratamentos cosméticos como o clareamento com recidivas e, ainda, facetas diretas com materiais resinosos que fracassaram ${ }^{18}$, são candidatos para o facetamento indireto. A vantagem principal da técnica indireta é o controle extrabucal da forma, caracterização, acabamento, polimento, devolução dos pontos ou faces de contato e adaptação da cerâmica ao término cervical. Laminados cerâmicos são promissores em termos de estabilidade de cor, alta resistência à fratura quando corretamente indicados e aderidos aos dentes, durabilidade, coeficiente térmico linear e dureza semelhante à dos tecidos dentários, bem como biocompatibilidade com os tecidos moles adjacentes pelo mínimo acúmulo de biofilme. Tais características são demonstráveis pelo alto potencial para uma adaptação marginal previsível de poucos micrômetros quando comparada com sistemas anteriores, que evoluíram em termos técnicos, além da manutenção da integridade do tecido periodontal subjacente e elevado grau de satisfação por parte dos pacientes.

\section{CONCLUSÕES}

A ansiedade gerada nos pacientes é plausível num mundo dinâmico e competitivo. Contudo, fases consideradas imperativas no procedimento reabilitador só podem ser postergadas quando um planejamento ordenado possibilite alternativas conservadoras e que não constituam empecilhos ao resultado final. A excelência da técnica dos laminados cerâmicos e dos materiais estéticos empregados tornam o arsenal terapêutico contemporâneo detentor de múltiplas possibilidades. Nunca o cirurgiãodentista foi tão competente em devolver a função, a estética e a satisfação psicológica para seus pacientes como no mundo moderno. 
ISSN 1983-5183

\section{REFERÊNCIAS BIBLIOGRÁFICAS}

1. SILVA W, Chimeli T. Transformando sorrisos com facetas diretas e indiretas. Rev Dent On Line 2011 abr-jun;10(21):41-3.

2. BISPO LB. Facetas estéticas: status da arte. Rev Dent On Line 2009 jan-mar;8(18):11-4.

3. SOARES PV, Zeola LF, Souza PG, Pereira FA, Milito GA, Machado AC. Reabilitação estética do sorriso com facetas cerâmicas reforçadas por dissilicato de lítio. ROBRAC 2012 jul-set;21(58):

4. CALAMIA JR. Etched porcelain facial veneers: a new treatment modality based on scientific and clinical evidence. NY J Dent 1983 Sep-Oct;53(6):255-9.

5. HORN HR. Porcelain laminate veneers bonded to etched enamel. Dent Clin North Am 1983 Oct;27(4):671-84.

6. CALAMIA JR, Simonsen RJ. Effect of coupling agents on bond strength of etched porcelain J Dent Res 1984 63(1):179.

7. CUNHA LF, Domingues RS, Furuse AY, Silva ER, Mondelli J, Mushashe A. Laminados cerâmicos na finalização dos tratamentos clínicos integrados. Rev Fac Odontol, Porto Alegre 2013 jan-dez;54((1-3)):31-4.

8. MENEZES MS, Carvalho EIA, Silva FP, Reis GR, Borges MG. Reabilitação estética do sorriso com laminados cerâmicos: relato de caso clínico. Rev Odontol Bras Central 2015 24(68):37-43.

9. FONSECA RB. Laminados cerâmicos: os 5W'. Nova Odessa: Napoleão; 2017.

10. CHAIN MC. Materiais dentários. São Paulo: Artes Médicas; 2013.

11. AMOROSO AP, Ferreira MB, Torcato LB, Pellizzer EP, Mazaro JVQ, Gennari Filho H. Cerâmicas odontológicas: propriedades, indicações e considerações clínicas. Rev Odontol Araçatuba 2012 jul-dez;33(2):19-25.

12. NAMORATTO LR, Ferreira RS, Lacerda RAV, Sampaio Filho HR, Ritto FP. Cimentação em cerâmicas: evolução dos procedimentos convencionais e adesivos. Rev Bras Odontol 2013 jul-dez;70(2):142-7.

13. D'ARCANGELO C, De Angelis F, Vadini M, D'amario M. Clinical evaluation on porcelain laminate veneers bonded with light-cured composite: results up to 7 years. Clin Oral Investig 2012 Aug;16(4):1071-9.

14. DUMFAHRT H, Schaffer H. Porcelain laminate veneers. A retrospective evaluation after 1 to 10 years of service: Part II--Clinical results. Int J Prosthodont 2000 Jan-Feb;13(1):9-18.

15. FRADEANI M, Redemagni M, Corrado M. Porcelain laminate veneers: 6- to 12-year clinical evaluation--a retrospective study. Int J Periodontics Restorative Dent 2005 Feb;25(1):9-17.

16. BURKE FJ, Lucarotti PS. Ten-year outcome of porcelain laminate veneers placed within the general dental services in England and Wales. J Dent 2009 Jan;37(1):31-8. 
Bispo LB. Laminados cerâmicos na clínica integrada. Rev. Odontol. Univ. Cid. São Paulo 2018 jan-mar; 30(1): 83-94

ISSN 1983-5183

17. PALMA-DIBB RG, Savaris C, Chinelatti MA, Lima FA, Bachmann L, Faraoni JJ. Composite photopolymerization: temperature increase according to light source and dentin thickness. J Dent Oral Implants 2016 1(1):11-9.

18. GUTIERREZ MF, Sutil E, Malaquias P, De Paris Matos T, De Souza LM, Reis A, et al. Effect of self-curing activators and curing protocols on adhesive properties of universal adhesives bonded to dual-cured composites. Dent Mater 2017 Jul;33(7):775-87.

RECEBIDO EM 04/09/2017

ACEIRO EM 23/10/2017 